\title{
Ben Highmore ja esteetiline uurijateadlikkus. Saateks
}

Epp Annus

Akadeemilised tõlkeartiklid valitakse tavaliselt nende kirjutiste hulgast, mis on juba klassikaks saanud või vähemalt on äratanud olulisel määral tähelepanu. Seekordne Methise tõlge on erandlik: tegu on artikliga, mis Methise trükkimineku ajaks polnud ajakirja Cultural Studies kaante vahel veel ilmunud. Nii et kui leidub lugeja, kes tellib endale nii ajakirja Methis kui Cultural Studies, siis ehk jõuavad artikli ingliskeelne algversioon ja eestikeelne tõlge tema lugemislauale üsna samal ajal.

Artikli värskus on seda olulisem, et artikli fookus on just käesolevas hetkes. Sussexi ülikooli professor Ben Highmore on üks Briti kultuuriuuringute juhtfiguuridest, mitmed tema viimase aja kirjutistest arutlevad kultuuriuuringute hetkeseisu üle, visandades sealjuures nii valdkonna ajaloolisi arengujooni kui pakkudes arengutrajektoore edaspidiseks (Highmore 2013, 2016). Siinne artikkel ongi huvitav kui mõtisklus kultuuri uurimise võimaluste üle käesolevas hetkes: Kuidas kirjutada? Millele tähelepanu pöörata? Millises laadis? Välja joonistub eneserefleksiivne, esteetikakeskne kirjutustrajektoor, kus uurija enda väljendusviis on tähtsustatud koos uurimisainele lähenemise laadiga.

Ben Highmore'i nimi on seotud mitmete Briti kultuuriuuringute suundadega. Küllap kõige olulisem on tema roll Briti argielu uuringute eestvedajana (Highmore 2002a, 2002b, 2009a, 2011, 2017a), aga tähtsal kohal tema kirjutistes on olnud ka metakriitilised refleksioonid kultuuriuuringute rolli, meetodite, eelkäijate teemadel (Highmore 2006, 2009a, 2015), lisaks on ta avaldanud käsitlusi arhitektuurist, disainist, linnakultuurist ja laiemalt visuaalkultuurist (Highmore 2005, 2009b, 2014, 2017b). 2000. aastal Londoni ülikooli Birkbeck College'is kaitstud doktoritöö eesmärgiks oli argielu tõstmine kultuuri-uuringute akadeemilise uurimisobjekti staatusesse, selle töö põhjal ilmus 2001. aastal „Argielu ja kultuuriteooria. Sissejuhatus“ („Everyday life and cultural theory: An Introduction“) ning samal aastal ka "Argielu lugemik“ („Everyday Life Reader“). Need „täpselt õigel ajal“ ilmunud raamatud avasid tee paljudele teistele, nii et 2009. aastal pidi Michael Gardiner juba tõdema, et angloameerika teadusmaailmas oli tekkimas argielu uurimuste uputus (Gardiner 2009: 383). ${ }^{1}$ 2005. aastal ilmus Highmore'i „Linnamaastikud“ („Cityscapes: cultural readings in the material and symbolic city“), 2006. aastal monograafiline käsitlus Michel de Certeau'st ja kultuurianalüüsi võimalustest („Michel de Certeau: analysing culture“). Järgnesid „Kultuurikired“ („A passion for cultural studies“, 2009) ja „Tavalised elud: uurimusi argipäevast“ („Ordinary lives: studies in the everyday“, 2011) - neis mõlemais on tähelepanu kesk-

1 Gardineri enda ülevaatlik „Critiques of everyday life: an introduction" oli samuti esimeste hulgas (Gardiner 2002). 
mes mitte ainult kultuuri kooshoidvad ideed ja tähendused, vaid ka energiad, meeleolud, kultuuri atmosfäär. Highmore'i sõnutsi: „Uskuda, et maailm on lame - see on lihtsalt arvamus, maailmale lisatud tähendus. Kaitsta tuliselt maailma lamedust ja eitada maa ümarust sellega juba siseneme kultuurikirgede maailma. See on kultuurivorm, mis läheb korda." (Highmore 2009: ix.)

2008. aastal ilmus Ben Highmore'i koostatud „Disainikultuuri lugemik“ („The Design Culture Reader"), 2014. aastal laiemale publikule mõeldud toast tuppa liikuv Briti kodu analüüs („The Great Indoors: At Home in the Modern British House“). 2015. aastal lisandus Routledge'i "Meedia- ja kultuuriuuringute põhiideede“ sarjas sissejuhatuslik „Kultuur“ („Culture“), 2017. aastal kaks raamatut korraga: kauaküpsenud käsitlus brutalismist 1950. aastate Briti tarbimiskultuuri taustal („The Art of Brutalism: Rescuing Hope from Catastrophe in 1950s Britain“) ning argielu-uurimuslik „Kultuuritunded“ („Cultural Feelings: Mood, Mediation and Cultural Politics“) - neist viimane jätkab „Kultuurikirgedes“ ja „Tavalistes eludes" alguse saanud nüüdisaegsete afektiteooriatega suhestuvat kultuuri meeleolude ja tundeväljade analüüsi.

Artiklis „Esteetiline on oluline: kirjutamine ja kultuuriuuringud“ on üheks põhiküsimuseks ratsionaalse argumentatsiooni ja maailma paljususe seos. Eks ole nii, et kirjutades me selekteerime, reastame, jätame midagi välja, rõhutame mingeid aspekte teiste arvel, tekitame loogilise terviku, mis vastab akadeemilise kirjutuse nõuetele, mida sobib esitada teaduskraadi kaitsmiseks või teaduslikule ajakirjale. Highmore'i sõnutsi leiab nii aset „maailma distsiplineerimine“, kusjuures sama tegevus toimub teadagi ka argielus, kus me paratamatult ei saa tähelepanu pöörata ilmaelu igale üksikasjale. Küsimus on aga, mis läheb sellise korrastamistegevuse juures kaotsi. Kas ei jää nii uurijale kättesaamatuks maailm selle paljususes, kus erisugused jõud, energiad, meeleolud, aistingud, praktikad, ideed esinevad kaootilises ja Iõputult kompleksses olekus, on pidevas muutumises ning vormivad pidevalt uusi vastasmõjude rägastikke? Highmore joonistab oma artiklis välja kultuuri-uuringute selle suuna, kus autorid on püüdnud hõlmata just nimelt maailma ilmnemise (worlding) mitmesust, on püüdnud tabada maailma olekut kui „kuuma segadust“ (hot mess), kui elavat komplekssust, mille edasiandmisel on üheks olulisemaks „tehnikaks“ kirjeldamine kui ilmakogemuse kõneldalaskmine. Hot mess -poeetika keskseks sümboliks tõuseb Highmore'i tekstis autoetnograafilist laadi vahepala, kus ta kirjeldab nii oma onu asju täis tuubitud eluruume kui ka Highmore'i enda - kultuurikriitiku - nii-öelda funktsionaalselt „valet“ pilku, mis omakorda huvitub asjadest korteris, selle asemel et sundida onu korterit korrastama. Highmore'i onu jaoks olid maailmast kadunud olulise ja ebaolulise hierarhiad, tema korterisse oli kuhjunud maailma paljusus sellisel viisil, et ka duširuum sai asjade ladestumise paigaks, selle esialgne funktsioon (pesemispaik!) oli kõrvale jäetud. Kultuurikriitiku pilk leiab sellest korterist elu kontsentraadi, perekonna mälukihid, aegade sadestused, funktsionaalse tegutsemise asendab esteetiline uuring. 
Teine, intellektuaalse ratsionaliseerimisega vahetult seotud valdkond, mis artiklis esile tõuseb, ongi intellektuaalse töö esteetika. Highmore tuletab siinkohal meelde Hayden White'i ajaloolise poeetika projekti ning tema algatatud humanitaaria ja sotsiaalteaduste „kultuuristamist" laiemalt. White'i projekti kaudu ei kerki mitte ainult küsimus intellektuaali esteetikast kui tekstiloome ühest võimalikust alustalast, vaid jõuame edasi ka loogiliselt järgmise küsimuse juurde: kui oleme juba saanud esteetiliselt teadlikuks uurijaks - s.t uurijaks, kes pöörab lisaks uurimisaine esteetilistele kvaliteetidele erilist tähelepanu ka omaenda kirjutuslaadile -, siis kuidas me mõistame uurija-esteetikat? Kas realistliku romaani, ulmekirjanduse või hoopiski tegevuskunsti paradigmas? Kas traditsiooniliselt stiililise heakõla ja väljenduseväljendatu harmoonia poole püüeldes või uute esteetiliste vormidega katsetades? Kas püüame lugejat šokeerida või valmistada lugejale meeldivalt sõnastatud tekstiga mõnusamat lugemiselamust? Poststrukturalismi kõrgaeg, meenutab Highmore, tõi akadeemilisse kirjutusse julget uuenduslikkust, mida ehk võiks kõrvutada tegevuskunsti või mõne ulmekirjanduse allhoovusega. Järgneval äratõukumisperioodil naasti „rahulikuma“ (ja ka igavama) kirjutuslaadi juurde - millest, olgem ausad, valdav enamik uurijaist kunagi ei eemaldunudki. Akadeemiline elu omandas rütmi „üks rahastustaotlus korraga“, epateerimine ning vormilis-keelelised-esituslikud mängud jäid tahaplaanile, üksikute erandlike figuuride päralt. Eesti publikule võiks siinkohal meenutada Tallinnaski esinenud Alphonso Lingist, kes pidas plenaarettekande taskulambi valgel, ettekande lehekülgi saalis laiali pildudes (ja kelle kirjutuslaad ei vaevu samuti traditsioonilist akadeemilist kaanonit jälgima).

Highmore'i artiklit lugedes võib tekkida küsimus, kas ei vii esteetiline lähenemine uurijatööle meid välja ilukirjanduse juurde. Eks ole ilukirjandus esmajoones esteetiliselt tundlik maailmakirjeldamise viis? Teame ju, et nüüdisaegne ilukirjandus ei pea tingimata sisaldama fiktsionaalset, väljamõeldud lugu. Kavalamad võivad intellektuaalse esteetika printsiipide taga tõepoolest näha võimalust kirjanikukalduvustega kirjutajale: elada akadeemilise uurija rohkem kindlustatud elu, taotleda teadusgrante, samal ajal kirjutades maskeeritud romaane. Selles suunas viitab ka Highmore'i artikli lõppakord, pöördumine Stephen Muecke fiktokriitiliste kirjutiste juurde (vt Muecke 2016). Ent Muecke tööd osutavad selgelt ka kvalitatiivsele erinevusele romaanikirjaniku ja fiktokriitiku vahel: tabavate kirjelduste ja haaravate olupiltide maalimise juurest jõuab Muecke välja tabavate kriitiliste sõnastusteni, ilukirjaniku stiilitaju raamib siin põhilaadilt analüütiline maailmatunnetus. Mõjukatest uurijatest on sellise balansseerimise heaks näiteks ka Kathleeni Stewarti kirjutised: Stewart on avaldanud nii romaane kui ka laialdast tähelepanu äratanud antropoloogilisi uurimusi, viimastes leidub rohkelt afektiivselt laetud olukirjeldusi, mis haaravad lugejat kaasa just sellesama tundejõuga ja maailma avastamise energiaga, mis on omased heale romaanile (vt Stewart 2007, 2016).

Hea kirjanik liigutab lugejat edasi mööda narratiivseid ahelaid, õnnestunud uurijatöö võib küll liikuda nii ilukirjanduslikus kui kriitilises registris, aga kirjutise edasiviiv dünaamika asetub siiski kriitilisse registrisse. Või mine tea? Highmore'i artiklis joonistub selgelt välja just 
neil päevil, otse meie silme ees asetleidev akadeemiliste ja ilukirjanduslike žanride piirjoonte järk-järguline hägustumine. Muidugi, see kõik on juba olnud, meenutagem või Roland Barthes'i hiliseid töid; žanre ja esitluslaade on ikka seganud ka feministlikud uurijad: Iugegem kasvõi Iris Marion Youngi haaravat autoetnograafilist vahepala oma lapsepõlvest ja ema võimetusest kodutöödega hakkama saada essees „House and Home“ (Young 2001). On

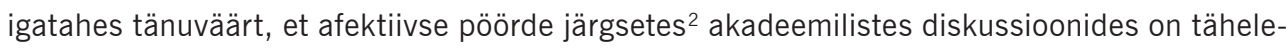
panu (taas) pöördunud uurijaesteetika võimalustele ning liigdistsiplineeritud akadeemiliste lähenemiste piiratusele. Selle diskussiooniga tasub kaasa minna.

\section{K i r j a n d u s}

Annus, Epp 2015. Afekt, kunst, ideoloogia. Aeglase teooria manifest. - Vikerkaar, nr 3, Ik 66-74. Gardiner, Michael 2002. Critiques of Everyday Life: An Introduction. London and New York: Routledge.

Gardiner, Michael 2009. Book Review: Philosophizing the Everyday: Revolutionary Praxis and the Fate of Cultural Theory, John Roberts (2006). London: Pluto. ISBN 0-745324-11-8. Everyday Life: Theories and Practices From Surrealism to the Present, Michael Sheringham (2006). Oxford. Space and Culture, No. 12 (3), pp. 383-388. - DOI: 10.1177/1206331209337667.

Highmore, Ben 2002a. Everyday Life and Cultural Theory. London and New York: Routledge.

Highmore, Ben [Ed.] 2002b. The Everyday Life Reader. The Everyday Life Reader. London and New York: Routledge. - DOI:10.1037/a0017668.

Highmore, Ben 2005. Cityscapes: Cultural Readings in the Material and Symbolic City. Basingstoke: Palgrave Macmillan.

Highmore, Ben 2006. Michel de Certeau: Analysing Culture. London: Continuum.

Highmore, Ben 2009a. Passion for Cultural Studies. Basingstoke: Palgrave Macmillan.

Highmore, Ben 2009b. The Design Culture Reader. London and New York: Routledge.

Highmore, Ben 2011. Ordinary Lives: Studies in the Everyday. London and New York: Routledge.

Highmore, Ben 2013. Feeling Our Way: Mood and Cultural Studies. - Communication and Critical/cultural Studies, No. 10 (4), pp. 427-38. - DOI: 10.1080/14791420.2013.840387.

High more, Ben 2014. The Great Indoors: At Home in the Modern British House. London: Profile Books.

Highmore, Ben 2015. Culture. London and New York: Routledge.

Highmore, Ben 2016. Formations of Feelings, Constellations of Things. - Cultural Studies Review, No. 22 (1), pp. 44-67. - DOI: 10.5130/csr.v21i1.4413.

Highmore, Ben 2017a. Cultural Feelings: Mood, Mediation, and Cultural Politics. London and New York: Routledge. 
High more, Ben 2017b. The Art of Brutalism: Rescuing Hope from Catastrophe in 1950s Britain. New Haven: Yale University Press.

Muecke, Stephen 2016. The Mother's Day Protest and Other Fictocritical Essays. Lanham: Rowman \& Littlefield International.

Stewart, Kathleen 2007. Ordinary Affects. Durham: Duke University Press.

Stewart, Kathleen 2016. The Point of Precision. - Representations, No. 135 (1), pp. 31-44. - DOI: 10.1525/rep.2016.135.1.31.

Young, Iris Marion 2001. House and Home: Feminist Variations on a Theme. - Feminist Interpretations of Martin Heidegger. Ed. by N. Holland, P. Huntington. University Park: Pennsylvania State University Press, pp. 252-88. 